\title{
Development and Application of Pyrolysis-Gas Chromatography/Mass Spectrometry for the Analysis of Bound Trinitrotoluene Residues in Soil
}

\author{
Jeffrey M. Weiss ${ }^{1}$, Amanda J. McKay ${ }^{1}$, Christopher DeRito ${ }^{1}$, Chuichi Watanabe ${ }^{2}$, \\ Kevin A. Thorn ${ }^{3}$ and Eugene L. Madsen ${ }^{1 *}$. \\ ${ }^{1}$ Department of Microbiology, Wing Hall, Cornell University, Ithaca, NY 14853 \\ ${ }^{2}$ Frontier Laboratories, Ltd., 1-8-4, Saikon, Koriyama, Japan \\ ${ }^{3}$ US Geological Survey, P.O. Box 25046 M.S. 408, Denver Federal Center, Denver, CO, \\ 80225-0046
}

\section{Supporting Information [nine pages including 4 figures (A-D)]}

Humic acid, a primary component of soil organic matter reacted with 2amino $\left({ }^{15} \mathrm{~N}\right)$-dinitrotoluene $\left[2-\left({ }^{15} \mathrm{~N}\right) \mathrm{ADNT}\right](12)$, was analyzed by single-shot analysis (SSA), evolved gas analysis (EGA), and double-shot analysis (DSA). Humic acid is more complex and representative of true soil than naphthoquinone (24). Therefore, humic acid provided a more realistic view of the applicability of pyrolysis for the analysis of reduced TNT compounds covalently bound to real-world, explosives-contaminated soil. Figure A displays a SSA-generated chromatogram for the complexed humic acid-2$\left({ }^{15} \mathrm{~N}\right)$ ADNT. Discerning a precise transition temperature in results from evolved gas analysis of the humic acid-2-( $\left.{ }^{15} \mathrm{~N}\right) \mathrm{ADNT}$ complex was not possible (Table 1). This was due to high background levels of relevant ions in the humic acid matrix. Based on previous results with monomeric ADNT (Table 1), it was expected that the transition 
temperature would fall between $200^{\circ}$ and $250^{\circ} \mathrm{C}$. Initial refinement of the transition temperature employed the DSA of clean (no TNT metabolites) humic acid spiked with monomeric 2-ADNT. Results from this analysis (Figure B) revealed a transition temperature of $225^{\circ} \mathrm{C}$. This value was confirmed by analyzing a synthetic humic acid-2$\left({ }^{15} \mathrm{~N}\right) \mathrm{ADNT}$ complex in which $2-\left({ }^{15} \mathrm{~N}\right) \mathrm{ADNT}$ was previously determined to be covalently bound to the humic acid. Due to the unavailability of the 4-amino isomer of ADNT, we determined the complete removal of added, monomeric 2-ADNT $\left({ }^{14} \mathrm{~N}\right)$ based on ion abundances. Figure $\mathrm{C}$ shows phase 1 results from the double-shot analysis of the humic acid-2-( $\left({ }^{15} \mathrm{~N}\right)$ ADNT complex with added, monomeric 2-ADNT $\left({ }^{14} \mathrm{~N}\right)$. Key ions for the ${ }^{15} \mathrm{~N}$ polymeric and ${ }^{14} \mathrm{~N}$ monomeric forms are $m / z=181$ and 180 , respectively. Mass spectral analysis of the 2-ADNT peak at 21.9 minutes found ions 180 and 181 at levels above those normally seen in the background. The phase 2 chromatogram is seen in Figure D. Examination of the 2-ADNT peak showed that only the parent ion corresponding to the complexed 2- $\left({ }^{15} \mathrm{~N}\right) \mathrm{ADNT}(\mathrm{m} / \mathrm{z}=181)$ was seen above background levels. Abundances of the parent ion characteristic of monomeric 2-ADNT $(m / z=180)$ were at background levels. These results further confirmed the ability of Py-GC/MS to distinguish between monomeric and covalently bound forms of ADNT and DANT in model systems. 


\section{Figure A}

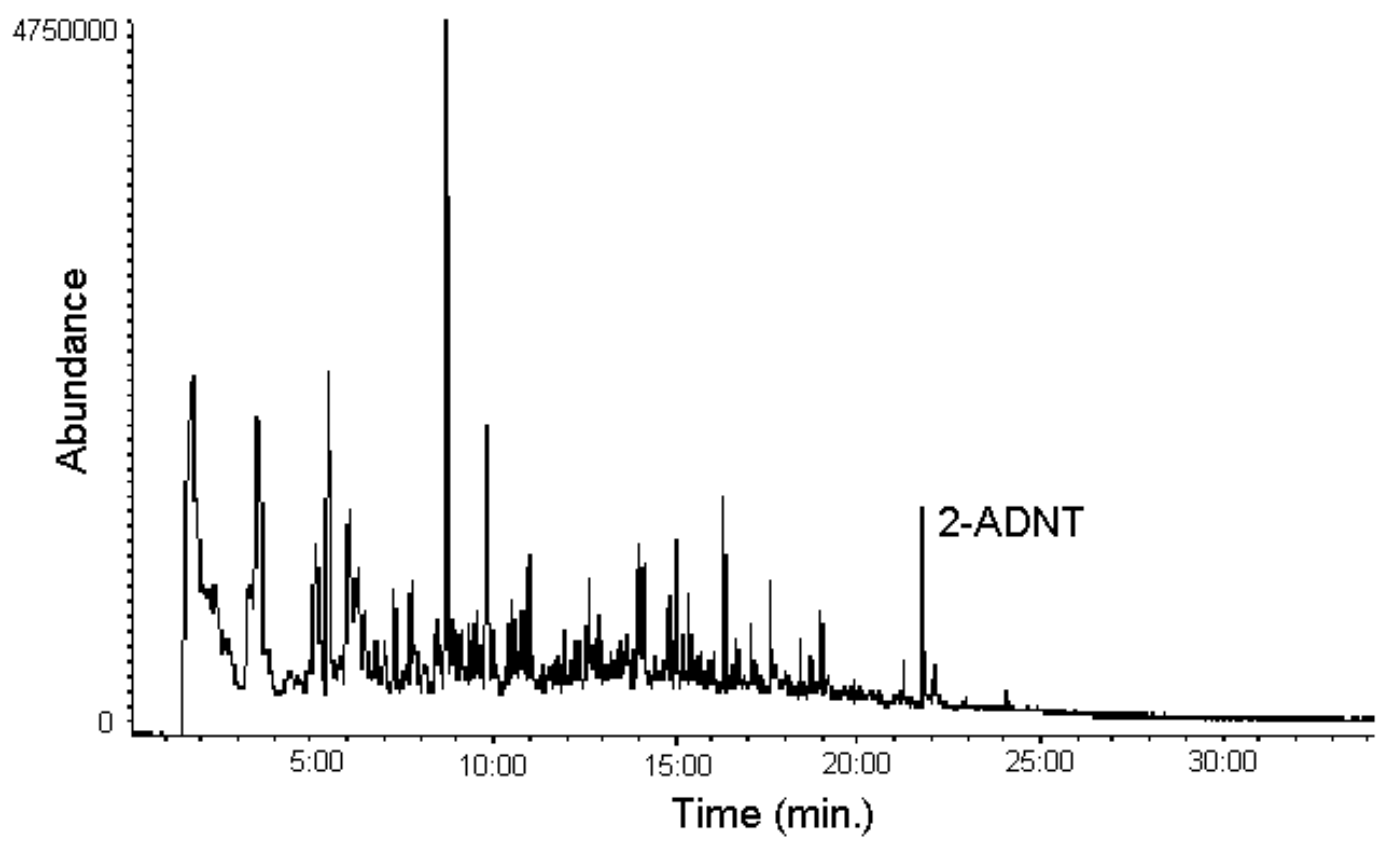

Figure A. Single-shot analysis of $2-\left({ }^{15} \mathrm{~N}\right)$ amino-dinitrotoluene (2-ADNT) covalently bound to humic acid. Pyrolysis at $400^{\circ} \mathrm{C}$ for 0.1 minutes. 


\section{Figure B}
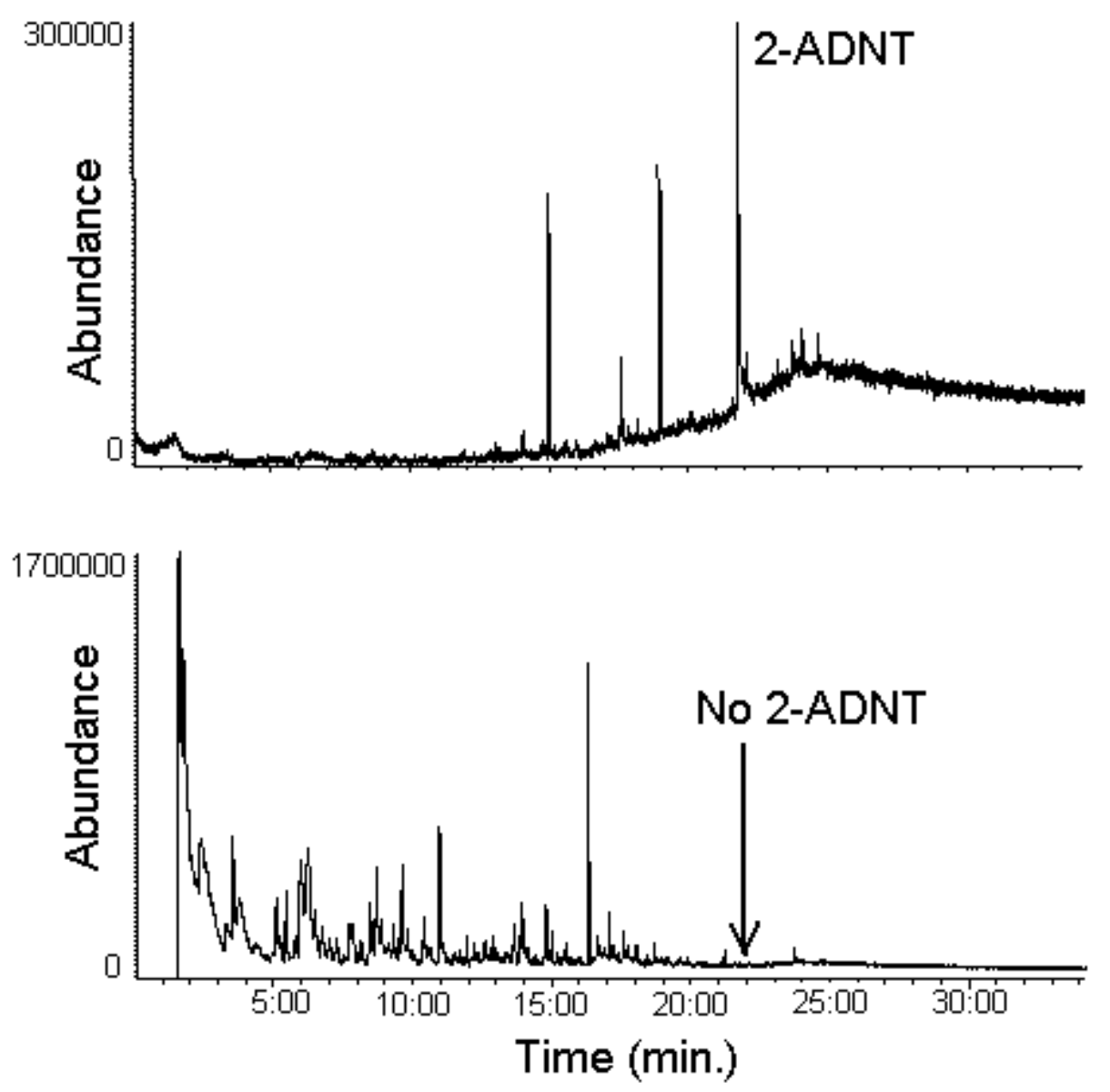

Figure B. Double-shot analysis of humic acid with added, monomeric 2-aminodinitrotoluene (2-ADNT). Phase 1: $100-225^{\circ} \mathrm{C}$. Phase 2: $400^{\circ} \mathrm{C}$. 


\section{Figure C}
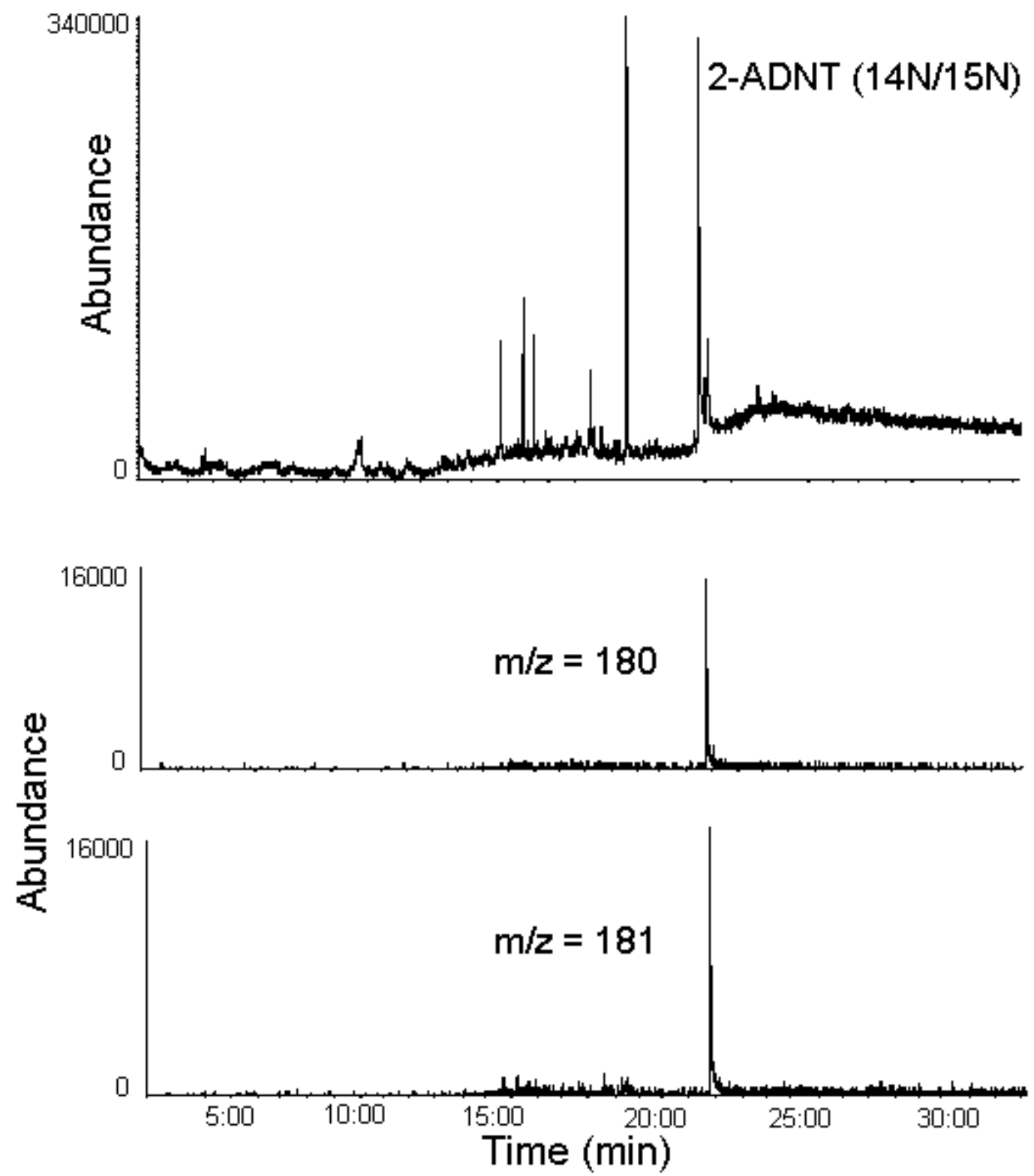

Figure C. Phase 1 of the double-shot analysis of the synthetic humic acid-2-( $\left.{ }^{15} \mathrm{~N}\right)$ aminodinitrotoluene (2-ADNT) complex and added, monomeric $2-\left({ }^{14} \mathrm{~N}\right)$ aminodinitrotoluene. Thermal desorption from $100-225^{\circ} \mathrm{C}$ was employed. Top panel shows total ion chromatogram. Lower panels display selected ion monitoring of ions 180 and 181, which are characteristic of the $\left({ }^{14} \mathrm{~N}\right)$ and $\left({ }^{15} \mathrm{~N}\right) 2$-ADNT compounds, respectively. 
Figure D
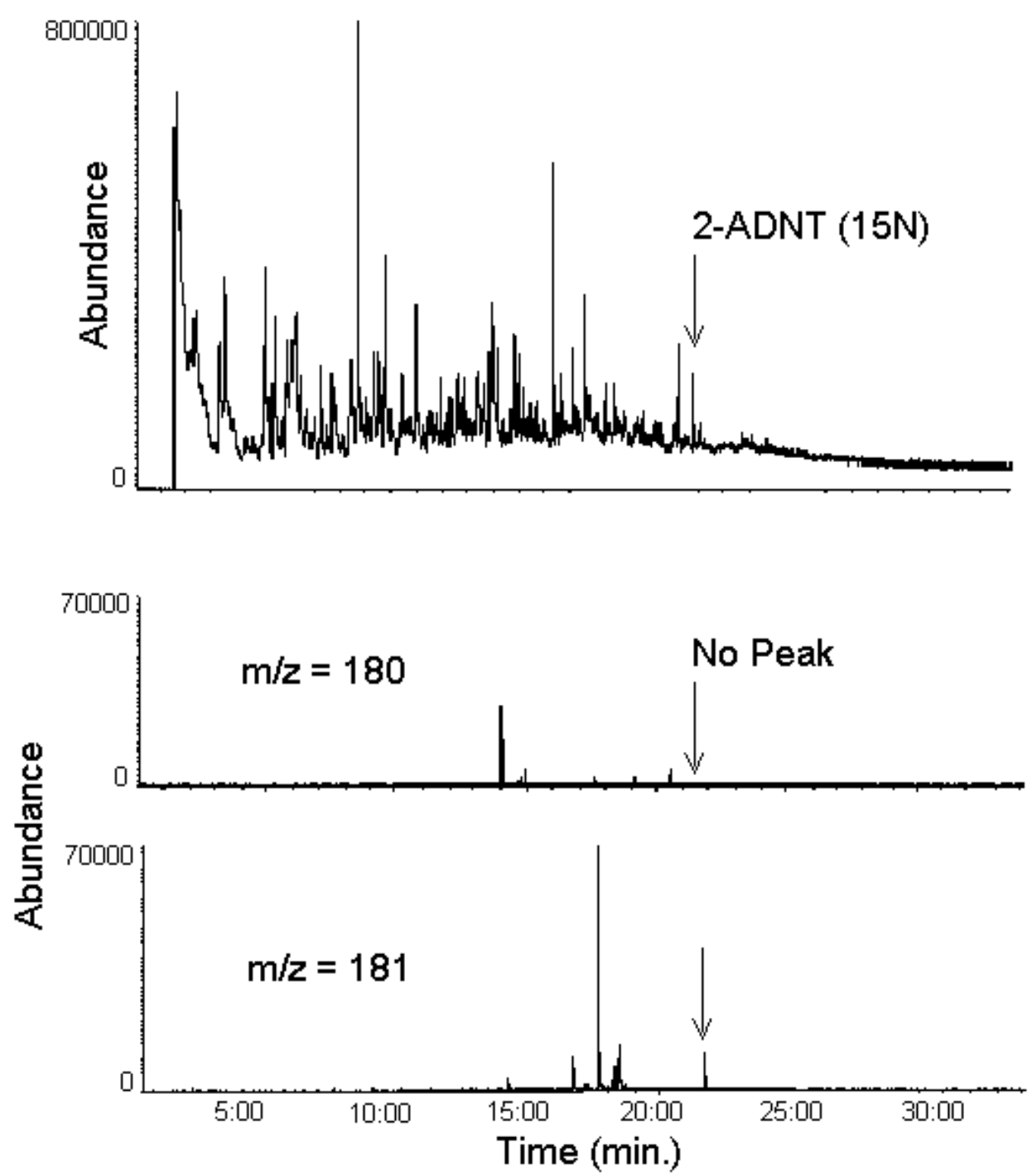

Figure D. Phase 2 of the double-shot analysis of the synthetic humic acid-2- $\left({ }^{15} \mathrm{~N}\right)$ aminodinitrotoluene (2-ADNT) complex and added, monomeric 2- $\left({ }^{14} \mathrm{~N}\right)$ amino-dinitrotoluene. Pyrolysis at $400^{\circ} \mathrm{C}$. Top panel shows total ion chromatogram. Lower panels display selected ion monitoring of ions 180 and 181, which are characteristic of the $\left({ }^{14} \mathrm{~N}\right)$ and $\left({ }^{15} \mathrm{~N}\right)$ 2-ADNT compounds, respectively. 
1. Spain, J. C. (2000) in Biodegradation of Nitroaromatic Compounds and Explosives (Spain, J.C.; Hughes, J.B.; Knackmuss, H.-J., Eds.), pp. 1-5, Lewis Publishers, CRC Press, New York.

2. Sciences International, Inc. (1995), U.S. Department of Health and Human Services, Public Helath Service, Agency for Toxic Substances and Disease Registry. http://www.atsde.cdc.gov/toxprofiles/tp81.html

3. Bruns-Nagel, D.; Steinbach, K.; Gemsa, D.; and von Low, E. (2000) in Biodegradation of Nitroaromatic Compounds and Explosives (Spain, J.C.; Hughes, J.B.; Knackmuss, H.-J., Eds.), pp. 357-393, CRC Press, Boca Raton, FL.

4. Thompson, P.L; Ramer, L.A.; and Schnoor, J.L. (1998) Environ. Sci. Technol. 32, 975-980.

5. Esteve-Nunez, A.; Caballero, A.; and Ramos, J.L. (2001) Microbiol. Molec. Biol. Rev. 65, 335-352.

6. Spiker, J.K.; Crawford, D. L.; and Crawford, R. L. (1992) Appl. Environ. Microbiol. 58, 3199-3202.

7. Lenke, H.; Achtnich, C.; and Knackmuss, H.-J. (2000) in Biodegradation of Nitroaromatic Compounds and Explosives (Spain, J.C.; Hughes, J.B.; Knackmuss, H.-J., Eds.), pp. 91-126, CRC Press, Boca Raton, FL.

8. Boopathy, R.; and Manning, J. (1999) Water Environ. Res. 71, 119-124.

9. Krumholtz, L.R.; Li, J.; Clarkson, W.W.; Wilber, G.G.; and Sulfita, J. (1997) J. Indust. Microbiol. Biotechnol. 18, 161-169.

10. Weber, E.J.;Colon, D.; and Baughman, G. L. (2001) Environ. Sci. Technol. 35, 2470-2475.

11. Achtnich, C.; Lenke, H.; Uwe, K.; Spiteller, M.; and Knackmuss, H.-J. (2000) Environ. Sci. Technol. 34, 3698-3704.

12. Thorn, K.A.; and Kennedy, K. R.(2002) Environ. Sci. Technol. 36, 3787-3796.

13. Bruns-Nagel, D.; Knicker, H.; Drzyzga, O.; Butehorn, U.; Steinbach, K.; Gemsa, D.; and von Low, E. (2000) Environ. Sci. Technol. 34, 1549-1556.

14. Khan, S.U. (1982) Res. Rev. 84, 1-25.

15. Ohtani, H.; Ueda, S.; Tsukahara, Y.; Watanabe, C.; and Tsuge, S. (1993) J. Anal. Appl. Pyrolysis 25, 1-10.

16. Sato, H.; Tsuge, S.; Ohtani, H.; Aoi, K.; Takasu, A.; and Okada, M. (1997) Macromolecules 30, 4030-4037.

17. Nakamura, S.; Takino, M.; and Daishima, S. (2001) J. Chromat. A 912, 329-334.

18. Thorn, K.A.; Pettigrew, P.J.; and Goldenberg, W.S. (1996) Environ. Sci. Technol. 30, 2764-2775.

19. Ononye, A.T.; Graveel, J.G.; and Wolt, J.D. (1989) Environ. Toxicol. Chem. 8, 303-308.

20. Achtnich, C.; Fernandes, E.; Bollag, J.-M.; Knackmuss, H.-J.; and Lenke, H. (1999) Environ. Sci. Technol. 33, 4448-4456. 
21. Dec, J.; and Bollag, J.-M. (1997) Soil Sci. 162, 858-874.

22. Ahmad, F.; and Hughes, J.B. (2002) Environ. Sci. Technol. 26, 4370-4381.

23. Elovitz, M.S.; and Weber, E.J. (1999) Environ. Sci. Technol. 33, 2617-2625.

24. Thorn, K.A. ;Pennington, J.C.; and Hayes, C. A.(2002) Environ. Sci. Technol. 36, 3797-3805.

25. Li, A.Z.; Marx, K.A.; Walker, J.C.; and Kaplan, D.L. (1997) Environ. Sci. Technol. 31, 584-589. 